\title{
Paulo Freire, seu legado com a dialética, educação popular e política
}

Deloíze Lorenzet ${ }^{1}$, Felipe Andreolla²

\begin{abstract}
Resumo
Este artigo versa sobre a produção de Paulo Freire, renomado educador brasileiro, conhecido internacionalmente, cujo maior destaque foi sua atuação política na preocupação com a libertação humana. Para ele, a educação de modo primordial é a capacidade de tornar-se humano, ou seja, envolver-se no processo de humanização. Neste artigo, por meio de uma reflexão teórica, realizamos um resgate das concepções formuladas por ele acerca dos conceitos de dialética, educação popular e política. Didaticamente, três pontos conduzem essa reflexão: os aportes teóricos que fundamentaram a dialética em Freire; a concepção de educação popular desenvolvida por Freire; e, por fim, o entendimento de Freire e a articulação entre educação e política. Em linhas gerais, Freire acredita na educação como uma ferramenta de transformação social, no diálogo como um modo de construção da liberdade e emancipação.
\end{abstract}

\section{Palavras-chave}

Freire. Dialética. Educação Popular. Política. Emancipação.

1. Doutora em Educação pela Universidade Federal do Rio Grande do Sul, Brasil; pedagoga do Instituto Federal de Educação, Ciência e Tecnologia Sul-Rio-Grandense, Campus Avançado Novo Hamburgo, Rio Grande do Sul, Brasil. E-mail: delolorenzet@hotmail.com.

2. Mestre em Educação pela Universidade Federal do Rio Grande do Sul, Brasil; gerente de operações das unidades do SENAI - Farroupilha, Garibaldi, Nova Prata e Veranópolis, Rio Grande do Sul, Brasil. E-mail: felipeandreolla@hotmail.com. 


\title{
Paulo Freire, his legacy with dialectics, popular education and politics
}

Deloíze Lorenzet* ${ }^{*}$ Felipe Andreolla**

\begin{abstract}
This article deals with the production of Paulo Freire, renowned Brazilian educator, known internationally, whose the great highlight was his political actions concerning the human liberation. To him, education, in a primordial way, is the capacity to become human, i.e., to be involved in the process of humanization. In this article, through a theoretical reflection we realize a rescue of the conceptions formulated by him on the concepts of dialectics, popular education and politics. Didactically, three points lead to this reflection: the theoretical contributions that grounded dialectics in Freire; the concept of popular education developed by Freire; and finally, Freire's understanding and the articulation between education and politics. In general, Freire believes in education as a tool of social transformation, in dialogue as a way of building freedom and emancipation.
\end{abstract}

\section{Keywords}

Freire. Dialectic. Popular Education. Politics. Emancipation.

* PhD in Education, Federal University of Rio Grande do Sul, Brazil; pedagogue of the Federal Institute of Education, Science and Technology Sul-Rio-Grandense, Advanced Campus Novo Hamburgo, State of Rio Grande do Sul, Brazil. E-mail: delolorenzet@hotmail.com.

* Master of Education, Federal University of Rio Grande do Sul, Brazil; operations manager of the SENAI units Farroupilha, Garibaldi, Nova Prata and Veranópolis, State of Rio Grande do Sul, Brazil.E-mail: felipeandreolla@ hotmail.com. 


\section{Introdução}

Este artigo tem por objetivos resgatar o entendimento de Freire acerca dos temas: dialética, educação popular e política, como também refletir, com base no referencial teórico freiriano, sobre a aprendizagem enquanto processo e o compromisso político que sustenta a proposta da educação emancipatória. A metodologia deste artigo científico consiste em uma revisão bibliográfica, com base em aspectos qualitativos. A principal referência teórica é Paulo Freire, reconhecido como educador de excelência e pela vasta produção bibliográfica.

Freire é um renomado educador pernambucano lembrado pela sua contribuição no campo da educação internacionalmente. Freire incansavelmente lutou pela educação, concebendo-a como a capacidade de tornar-se humano, "ser mais". Em uma de suas publicações de maior destaque, Pedagogia do Oprimido (2003), na qual são tecidas críticas ao modelo bancário de educação, o argumento central é a defesa de uma pedagogia crítico-libertadora em que cada cidadão é compreendido como sujeito da história. Em 2018, a referenciada obra completou 50 anos de existência, sendo já traduzida para mais de 20 idiomas.

Paulo Freire nasceu na região Nordeste do Brasil, em Recife, Pernambuco, no dia 19 de setembro de 1921 e faleceu em São Paulo, no dia 2 de maio de 1997. Um aspecto pelo qual mereceu destaque foi sua preocupação com o grande número de adultos analfabetos na área rural dos estados nordestinos, que formava um grupo significativo de excluídos. Para resolver essa situação desafiadora, Freire desenvolveu um método de alfabetização baseado no vocabulário do cotidiano e da realidade daqueles sujeitos. As palavras geradoras eram discutidas e colocadas no contexto social do indivíduo. Para exemplificar: o agricultor aprendia as palavras: cana, enxada, terra, colheita etc. e era levado a pensar nas questões sociais, econômicas e históricas relacionadas ao seu trabalho. A partir das palavras-base eram construídas novas palavras e ia-se ampliando o vocabulário. A iniciativa do educador foi aplicada pela primeira vez, em 1963, na cidade de Angicos, no sertão do Rio Grande do Norte, quando foram alfabetizados 300 trabalhadores da agricultura. O projeto ficou conhecido como "Quarenta horas de Angicos".

Por seu trabalho na área educacional, Paulo Freire é reconhecido mundialmente. É o brasileiro com mais títulos de Doutor Honoris Causa de diversas universidades, são 41 ao todo, dentre elas, Harvard, Cambridge e Oxford.

Freire desenvolveu uma trajetória com preocupação política e educativa, também subentendeu a educação como um direito indistinto, pautada em concepção de gestão democrática. Afirmou seu compromisso com maior justiça social, solidariedade e equidade, superando preconceitos e desigualdades.

As questões que delinearam essa pesquisa foram: a) De que modo Freire apropriou-se da dialética? Quais os aportes teóricos que o inspiraram? b) Como foi que Freire desenvolveu a proposta pedagógica da Educação Popular? Em que consiste? c) De acordo com Freire, qual a interlocução entre educação e política?

Com base nessas indagações desenvolvemos este artigo científico que reconhece em Freire um educador de excelência. Posteriormente, desenvolveremos o referencial teórico deste artigo na tentativa de elucidar a problematização exposta anteriormente. 


\section{Referencial teórico}

Estruturalmente este tópico está subdividido em três partes: a primeira referente ao conceito de dialética; a segunda diz respeito ao conceito de educação popular, e, por fim, a terceira parte resgata o tema educação e política.

\section{Freire e a Dialética}

A obra de Paulo Freire tem por princípio o uso do método dialético. Segundo Zitkoski na descrição do verbete "dialética", disponível no Dicionário Paulo Freire (2015), publicado em espanhol, em Lima (Peru), há em Freire um retorno às origens gregas ao repensar a relação dialética e diálogo:

La originalidad de Freire está en la superación de una forma de pensar totalizadora de la vida, pues él busca construir crítica y creativamente nuevos elementos para concebir la vida humana en sociedad de un modo radicalmente democrático y liberador. Al elaborar una nueva visión epistemológica a partir de la producción del conocimiento de forma dialógica, intersubjetiva y dialécticamente abierta al dinamismo de la vida, la diferencia y lo inédito viable, inspira además profundas innovaciones en la visión política y ética de los problemas que desafían al mundo actual. (ZITKOSKI, 2015, p. 150).

Desse modo, Zitkoski (2015) defende que Freire é um teórico plural, com mente aberta, ideias largas, pois constrói criticamente e criativamente novos argumentos sobre diferentes aspectos como a vida, a sociedade, o mundo. Destaca que Freire afastou-se da dialética no seu sentido clássico, apropriando-se dela pela importância do lugar da tomada de consciência, como uma ferramenta problematizadora da realidade concreta pelos seres humanos em situação de desumanização. Dessa forma, também utilizou da dialética para a compreensão mais esclarecedora acerca do problema das contingências (antítese), com o questionamento da predominância de uma posição sobre outra, fazendo com que o diálogo libertador, em busca de uma síntese, seja aberto a uma horizontalidade da busca, permanentemente investigativo, crítico, atento ao novo que reinventa uma práxis humana emancipatória.

Para Fonseca et al. (2016), de acordo com Freire, a relação opressor/oprimido busca por um lado a emancipação das injustiças decorrentes da exploração do trabalho, por outro lado, afirma ser uma tarefa coletiva da construção do sentido no processo de humanização. Freire apropriase de estudos de Hegel, filósofo alemão, e tal influência acontece em sua produção. "Dessa forma, pressupõe-se que a filosofia de Hegel influencia a noção de libertação de Freire, enquanto comunhão" (FONSECA, 2016, p. 35). Freire afirma que o processo de libertação não ocorre isoladamente, mas em comunhão, mediados pela realidade social e histórica.

Conforme Hegel, a dialética é um movimento, uma estrutura, ou até uma lógica do "vir-a-ser". Para Hegel, a dialética e a ciência estão imbricados, ou seja, há um movimento, em espiral para a construção do conhecimento. Fonseca et al. (2016, p. 36) nos auxiliam ao anunciar:

O termo dialética tem sua origem no termo grego dialektiké, termo composto de lego, que significa falar e diá, que significa através de, por meio de. Entre os gregos, indicava o diálogo, a arte da discussão. Em Hegel, a dialética explica a mudança pela contradição.

O método dialético também é desdobrado em três momentos: 1) da tese ou sincrese; 2) da antítese; 3) da síntese.

O primeiro momento, da tese ou da sincrese, diz respeito a uma visão caótica do objeto, o pensamento afirma determinada posição. Poderíamos dizer que são as primeiras impressões, as leituras prévias que temos sobre 
a verdade ou a realidade. Como atividade intelectiva, esse momento é importante para o pensar sistemático, pois inicia uma trajetória, mas não pode permanecer nele, deve passar adiante.

O segundo momento, da antítese, é um momento de contradições, de oposições, de conflito, de confronto, de dar-se conta das falhas e das inconsistências. É um momento de despertar crítico, buscando uma reconciliação, como se fosse uma nova unidade entre esses saberes opostos.

O terceiro momento, a síntese, caracterizase pela capacidade de apreender, de superar o confronto e absorver e conservar formulando nova unidade. A síntese vem a ser a culminância dos dois processos anteriores, superando-os. Após a realização da síntese, todo processo pode ocorrer novamente, progredindo sempre para um saber mais abrangente e melhor estruturado.

Freire também se apropria de algumas concepções desenvolvidas por Marx, a exemplo tem-se o conceito de práxis, no qual é colocado como ponto de partida o concreto, a realidade de cada sujeito e após há uma reflexão sobre essa prática, no sentido de ação-reflexãoação. A práxis, de modo amplo, diz respeito a uma ação e reflexão intersubjetiva que leva à constante transformação do mundo.

Nos estudos desenvolvidos por Freire, publicados em A importância do ato de ler, o autor revela que não é pertinente a insistência na quantidade de leituras sem a devida compreensão, pois, para ele o importante é a qualidade do texto, esclarecendo que "um dos documentos filosóficos mais importantes que dispomos, As teses sobre Feuerbach, de Marx (1845), tem apenas duas páginas e meia" (FREIRE, 2011, p. 27). Nessa afirmação, Freire confirma a relevância dessa contribuição como um dos pressupostos de sua pedagogia. Nesse mesmo referencial, admite que a educação deve ofertar uma compreensão diferente das injustiças.

Énesse sentido que a leitura crítica da realidade, dando-se num processo de alfabetização ou não e associada sobretudo a certas práticas claramente políticas de mobilização e de organização, pode constituir-se num instrumento para o que Gramsci chamaria de ação contra-hegemônica. (FREIRE, 2011, p. 31).

Seguindo ainda a influência marxista, Freire aborda que a conscientização é constituída a partir da ação humana pelo trabalho, ou seja, o trabalho humano e as relações que se estabelecem são fundamentais para a formação da consciência. Para Freire também é essencial que a consciência enquanto processo seja formulada em confronto com a alteridade, com o outro, um processo que não ocorre separadamente dos demais, pois é uma atitude crítica e se dá em interação comunicativa a partir de problematizações com outros sujeitos, em suas circunstâncias históricas e culturais. Outra característica que perpassa toda a obra e pensamento freiriano é a contextualização. Para Freire, o conhecimento é uma informação contextualizada.

$\mathrm{Na}$ continuidade desse referencial teórico abordaremos como Paulo Freire concebeu a proposta da Educação Popular

\section{Freire e a Educação Popular}

Para Freire a educação se encontra ancorada em dois pilares: na consciência humana de sua incompletude e, ainda, na vocação histórica e ontológica para ser mais, em outras palavras, para buscar a humanização. Nesse sentido, a aprendizagem é concebida como um processo contínuo, de reformulação do nível de compreensão e não como algo estável e acabado, mas em contínuo movimento. De acordo com a obra Pedagogia da Autonomia, educar "não é transferir conhecimento, mas criar as possibilidades para a sua própria produção ou a sua construção" (FREIRE, 2002, p. 52). Uma das principais sistematizações de 
Freire encontra-se na tese apresentada para a Universidade de Recife, intitulada Educação e atualidade brasileira. Posteriormente, essa tese originou a publicação do livro Educação como prática de liberdade. Essa obra sintetiza algumas das convicções e opções epistemológicas, políticas e pedagógicas, permitindo o surgimento de uma nova concepção de educação: a educação popular.

Segundo Paludo (2001, p. 91), "é nos anos 1960, com Paulo Freire, que se tem, pela primeira vez, de forma consistente, uma pedagogia anunciada das classes populares" Tal iniciativa leva em consideração a realidade brasileira, em que as classes populares assumem papel central.

Em linhas gerais, a educação popular pode ser compreendida como uma nova forma de compreender a educação, especialmente na América Latina. Uma das premissas da educação popular é a busca da transformação ao invés da conservação ou reprodução social. Esse formato de educação aposta nos movimentos populares, na cultura popular, na tentativa de emancipar os sujeitos, essa proposta está vinculada a um projeto sociopolítico libertador.

Para Paludo, que desenvolveu o verbete educação popular, disponível no Dicionário Paulo Freire (2015), publicado em espanhol, em Lima (Peru), essa educação é feita com o povo, como sujeitos, protagonistas de sua emancipação.

En síntesis, para Freire la educación popular designa la educación hecha con el pueblo, con los oprimidos o con las clases populares, a partir de un mismo tiempo gnoseológico, político, ético y estético (FREIRE, 1997). Esta educación, orientada a la transformación de la sociedad, exige que se parta del contexto concreto/vivido para llegar al contexto teórico, lo que requiere la curiosidad epistemológica, la problematización, la rigurosidad, la creatividad, el diálogo, la vivencia de la praxis y el protagonismo de los sujetos. (FREIRE, 1995).

A principal obra de Freire, referência mundial, é a Pedagogia do Oprimido. Nela é apresentada uma crítica à concepção bancária de educação, que leva à domesticação, considerando os estudantes tábulas rasas a serem preenchidas pelos depósitos do professor. Nessa concepção, o professor, professa, transfere conhecimentos e convicções, por meio da imposição, não gerando comunicação, pois não há diálogo, com confronto de opiniões e reciprocidade de trocas, não gerando conhecimento. Freire anuncia: "Só existe saber na invenção, na reinvenção, na busca inquieta, impaciente, permanente, que os homens fazem no mundo, com o mundo e com os outros. Busca esperançosa também" (FREIRE, 2003a, p. 66).

Outra premissa que o autor retoma é da necessidade de aproximação com outros sujeitos para que ocorra o processo de aprendizagem: "ninguém educa ninguém, ninguém se educa a si mesmo, os homens se educam entre si, mediados pelo mundo" (FREIRE, 2003a, p. 68). Ou seja, educar exige a presença dos demais, dos outros, do encontro, do coletivo.

Acerca desse envolvimento com sujeitos diferentes também expõe que não deve haver superioridade ou inferioridade, pois, há níveis de aprendizagem diferenciados e experiências de vida que permitem saberes diferentes: "Ninguém ignora tudo. Ninguém sabe tudo. Todos nós sabemos alguma coisa. Todos nós ignoramos alguma coisa" (FREIRE, 2011, p. 84).

Para Paludo, em sua obra, Educação popular em busca de alternativas,

É importante explicitar que, para Freire, a opressão não se reduz à dimensão da exploração econômica, abrange, também, a dominação cultural e política, as discriminações étnicas, de gênero, religiosas e de orientação sexual, bem como as relações predatórias com a natureza. Todas estas opressões são condicionantes construídos historicamente que impedem o homem de realizar sua vocação humana no sentido de "ser mais". (PALUDO, 2001, p. 79). 
De acordo com essa visão, a educação popular é uma prática educativa que se propõe a ser diferenciada, isto é, compromissada com os interesses e a emancipação das classes subalternas. Assim, passaremos para o próximo tópicoem que ressaltamosa conexãoapresentada por Freire entre a educação e dimensão política.

\section{Freire e a Política}

Freire foi um educador com opção política. Ele tinha clara radicalidade em sua opção a favor dos oprimidos e injustiçados, sua prática possuía um posicionamento assumido a favor das classes populares. De acordo com sua concepção, não existe neutralidade nos processos educativos, pois qualquer processo tem por objetivo uma finalidade, revelando decisões, opções, convicções, direção, ou seja, tem uma implicância política.

Paulo Freire, em sua história de vida, passou por situações de fome, fazendo com que desde cedo, descobrisse materialmente que havia algo de errado com essa sociedade, e segundo seu entendimento, merecia ser consertado. Para Freire, a sociedade era desigual e esse fenômeno não era um fatalismo e nem um determinismo histórico ou natural, mas devido aos interesses de alguns "dominantes".

Freire atuou junto ao Sesi, trabalhou com pescadores/as, camponeses/as e trabalhadores/ as urbanos/as. Dessa experiência teve contato com a dramaticidade da vida desses/as trabalhadores/as explorados/as, muitas vezes desanimados/as e sem esperanças de um futuro melhor. Tais vivências fizeram com que ele valorizasse o saber popular e também dedicasse maior rigor para compreender criticamente a situação desses trabalhadores/as. Assim, refletia:

Não resisto à tentação de [...] chamar a atenção para a relação entre níveis profundos de violência de classe, de exploração de classe, cansaço existencial, anestesia histórica, fatalismo diante de um mundo considerado como imutável e ausência de consciência de classe entre dominados e violentados. Por isso, à medida que começam a se comprometer com a luta política, aprendendo a vivê-la, a enfrentá-la em seus diferentes aspectos, mobilizando-se, organizando-se para a transformação da sociedade, vão se assumindo como "classe para $\mathrm{si}^{\prime}$, superam o fatalismo que os "anestesiava" historicamente. (FREIRE, 2003b, p. 46).

Com base nessas ideias, Freire e toda uma equipe do Serviço de Extensão Cultural da Universidade do Recife dedicaram-se a desenvolver um método de alfabetização que buscasse conciliar a consciência crítica e o engajamento político.

Outra causa de enorme relevância em sua trajetória era a defesa pela democracia. Segundo Freire, os processos democráticos envolvem a luta pela justiça e pelos direitos fundamentais, em que todos, indistintamente, devem ter supridas suas necessidades básicas e ainda o direito ao respeito, sem sofrer discriminações, em virtude da orientação religiosa, sexual, origem racial, situação socioeconômica, diferença de gênero ou por outros fatores.

O educador destaca em sua obra Cartas a Cristina:

O ensino da democracia implica também o discurso sobre ela, não abstratamente feito, mas sobre ela ao ser ensaiada e experimentada. Discurso crítico, bem fundado, que analisa, concretamente, os seus descompassos, suas incoerências. Discurso teórico, emergindo da compreensão crítica da prática, eticamente baseado. (FREIRE, 2003a, p. 201).

Nesse sentido, a democracia deve ser vivenciada, não apenas discutida. É primordial ainda que a democracia esteja aliada ao conceito de justiça social, determinantemente contrária a qualquer forma de preconceito e de violência, buscando a superação das desigualdades.

Segundo a pesquisadora Daianny Costa, que contribuiu na síntese do verbete 
Política disponível no Dicionário Paulo Freire (2015), publicado em espanhol em Lima (Peru), há o entendimento de que a educação é um ato político, pois é pensada a favor de uns e não de outros, e nesse sentido, a educação progressista, emancipadora, precisa comprometer-se com as classes populares.

Me gusta ser persona porque, siendo inacabado, sé que soy un ser condicionado pero, consciente del inacabamiento, sé que puedo ir más allá de él. Esta es la diferencia profunda entre el ser condicionado y el ser determinado (FREIRE, 1996, p. 59). En eso reside nuestra condición política. En la condición de sujeto histórico y político, fue produciendo una obra que buscó la comprensión de la sociedad moderna en la cual estaba inserto, o sea, reconoció la lucha de clases y la consecuente producción de oprimidos y opresores, como constructo humano y, por eso, capaz de ser reinventado por medio de la conciencia política, de la liberación del opresor existente en cada uno de nosotros. (FREIRE, 1999).

Desse modo, a educação intrinsecamente precisa ter envolvimento político, ao tomar decisões, definir opções, assegurar a aprendizagem e a responsabilidade política e social, vinculada a uma sociedade democrática, com cidadãos participativos que lutam por uma sociedade mais solidária.

Na obra A importância do ato de ler (2011), no Prefácio, elaborado por Antônio Joaquim Severino, há a afirmação de que Freire produz sua obra pautada em educação política, retomando que a leitura do mundo precede a leitura da palavra, pois a alfabetização e a educação implicam em aprender a ler o mundo, compreender o seu contexto, numa relação dinâmica entre linguagem e realidade.

Ademais, a aprendizagem da leitura e a alfabetização são atos de educação e educação é um ato fundamentalmente político. Paulo Freire reafirma a necessidade de que educadores e educandos se posicionem criticamente ao vivenciarem a educação, superando as posturas ingênuas ou "astutas", negando de vez a pretensa neutralidade da educação. (SEVERINO apud FREIRE, 2011, p. 14).

Dando sequência na obra identificada como uma referência sobre a alfabetização e sua conotação política, Freire alerta que a neutralidade da educação "de que resulta ser ela entendida como um quefazer puro, a serviço da formação de um tipo ideal de ser humano, desencarnado do real, virtuoso e bom, é uma das conotações fundamentais da visão ingênua da educação" (FREIRE, 2011, p. 40).

Nesse campo, as políticas educacionais indicam o papel do Estado como uma superestrutura que envolve as dimensões municipal, distrital, estadual e federal, mediante a soma de esforços na garantia do direito à educação. De modo mais setorial, as políticas públicas educacionais devem ser orientadas por prioridades, vínculos e compromissos, catalizando suas ações. De acordo com Dourado (2011, p. 27-28),

As políticas públicas no campo da educação, materializadas por meio de práticas sociais, não possuem autonomia diante da realidade social mais ampla, da qual são partes constitutivas e constituintes. $\mathrm{Na}$ medida em que se configuram como ato político, expressam sempre uma tomada de posição, uma concepção de mundo, de homem, de sociedade e de educação. A ação educativa e, consequentemente, a política educacional, em qualquer de suas feições, não possuem apenas uma dimensão política; são sempre políticas, já que não há conhecimento, técnica e tecnologia neutros, pois todos são expressões de formas conscientes, ou não, de engajamento.

Conforme o exposto, as políticas educacionais possuem disputas e atendem a alguns direcionamentos, ou seja, possuem um posicionamento e apoiam determinados fins. 
É oportuno afirmar que nossas experiências democráticas ainda são incipientes e necessitamos aprofundar as experiências. Uma forma de qualificar essa participação e envolvimento é por meio da gestão democrática. Para Lück (2014, p. 111),

Gestão educacional corresponde ao processo de gerir a dinâmica do sistema de ensino como um todo e de coordenação das escolas em específico, afinado com as diretrizes e políticas educacionais públicas, para a implementação das políticas educacionais e projetos pedagógicos das escolas, compromissado com os princípios da democracia e com métodos que organizem e criem condições para um ambiente educacional autônomo (soluções próprias, no âmbito de suas competências) de participação e compartilhamento (tomada de decisões conjunta e efetivação de resultados), autocontrole (acompanhamento e avaliação com retorno de informações) e transparência (demonstração pública de seus processos e resultados).

Cabe ressaltar que Freire exerceu função de gestão como Secretário Municipal de Educação da cidade de São Paulo de 1989 a 1991. Ou seja, além de contribuir teoricamente, exerceu na prática atividades que fizeram a diferença no campo da educação.

\section{Considerações finais}

A contribuição de Paulo Freire é de extrema relevância educacional e social. Esse educador é reconhecido internacionalmente por sua epistemologia política e pedagógica. Debater as ideias de Freire no contexto atual é de enorme relevância, uma vez que vivenciamos a condução dos processos políticos, por meio de "reformas", ou seja, uma condução autoritária dos processos, marcada por movimentos unilaterais e conservadores. Em tais atuações percebemos um antidiálogo e resultados que produzem "contrarreformas", destruindo e fragilizando a democracia. Frente a esse cenário, dialogar com as concepções de Freire é reconhecer seu posicionamento progressista e afirmar a defesa por uma educação emancipatória, é afirmar a resistência pelos processos democráticos. Por ser um artigo científico de natureza qualitativa, espera-se que tenha realizado uma contribuição para o melhor entendimento científico desenvolvido por Freire no tocante aos conceitos de dialética, educação popular e política, conforme o objetivo enunciado e também, que tenha provocado a reflexão de que a aprendizagem ocorre por meio de um processo, buscando o tornar-se humano, o vir-a-ser e o ser mais.

Reafirma-se o legado de Freire em relação à dialética, uma vez que assume a pluralidade, as diferenças: nas formas de compreensão, nas formas de convivência, nos lugares de produção de seus modos de vida, superando as compreensões totalizadoras, colocando-se aberto ao diálogo libertador. Nesse sentido, o processo dialético deve ser crítico e criativo a partir de uma consciência problematizadora das situações opressoras.

No tocante à educação popular, Freire (2011, p. 99-100) assim explica acerca da transformação da sociedade provocada pelo processo educativo:

O homem novo e a mulher nova não aparecem por acaso. O homem novo e a mulher nova vão nascendo na prática da reconstrução revolucionária da sociedade. Mas, de qualquer maneira, podemos pensar em algumas qualidades que caracterizam o homem novo e a mulher nova. O compromisso com a causa do Povo, com a defesa dos interesses do Povo é uma destas qualidades.

Conforme evidenciamos em Freire, a possibilidade da construção do homem e da mulher nova desenvolve-se num processo intencional, tal processo é o cerne da educação popular. Na sequência, Freire realiza uma defesa 
em relação à autonomia, à liberdade, à igualdade e à solidariedade, que pavimentam o caminho da libertação e salientam que por meio da participação política, coletivamente, podemos lutar por uma reconstrução da sociedade. Sob a relação entre educação e política, destaca-se que sua atuação profissional e acadêmica foi política, em defesa dos esquecidos, oprimidos e explorados. O próprio método de alfabetização foi político ao transformar vidas, oportunizando novas chaves de leitura do mundo que precediam a leitura da palavra. Enfatiza-se, ainda, que todo ato educativo é político na medida em que tem um compromisso com a proposta da educação emancipatória e que salienta a dimensão democrática em detrimento dos modos de condução autoritários.

Frente a essas colocações, resgatamos alguns dizeres de Ferreira (2011, p. 7) que, de modo semelhante a Freire, afirma que precisamos ter esperanças:

Esperança de que possamos construir um mundo mais justo e humano, porque a história dos homens e de suas instituições é feita pelos homens que fazem a vida e constroem o mundo. Esperança é possibilidade. Possibilidade de continuar a fazer acontecer.
Não existe esperança sem um horizonte, e esse horizonte é o futuro que necessita ser construído por todos nós.

Essa mesma esperança é avaliada por Freire como indispensável, essencial. E, assim, as palavras finais desta reflexão são oriundas do verbete Esperança, disponível no Dicionário Paulo Freire (2015), publicado em espanhol em Lima (Peru), como contribuição do pesquisador Danilo Streck (2015, p. 202):

Esperanza es una categoría central en la obra de Freire, vinculada con otros conceptos como utopía, inédito viable o sueño posible. Ya en Pedagogia do oprimido (1981b, p. 97) la esperanza se hace presente como condición para el diálogo, junto con el amor, la humildad, la fe en los hombres y en las mujeres. La confianza se instaura en el dialogo que, a su vez, es movido por la esperanza. El diálogo en busca del ser más, no puede darse en la desesperanza.

Nesse sentido, tais valores, como a esperança, o amor, a humildade, o diálogo e o respeito devem estar presentes em qualquer sociedade, em seus diversos contextos, educacionais, políticos, econômicos, para que novos tempos sejam descortinados.

\section{Referências}

COSTA, D. Política. In: STRECK, D. R.; REDIN, E.; ZITKOSKI, J. (org.). Dicionário Paulo Freire. Lima: CEAAL, 2015. p. 402-404. Doi: 10.5007/2175-7984.2015v14n30p56.

DOURADO, L. F. Plano Nacional de Educação: avaliações e retomada do protagonismo da sociedade civil organizada na luta pela educação. In: FERREIRA, N. S. P. (org.). Políticas públicas e gestão da educação: polêmicas, fundamentos e análises. Brasília: Liber Livro Editora, 2011. p. 21-48.

FERREIRA, N. S. C. (org.). Políticas públicas e gestão da educação: polêmicas, fundamentos e análises. Brasília: Liber Livro Editora, 2011. 192 p.

FREIRE, P. A importância do ato de ler: em três artigos que se completam. 51. ed. São Paulo: Cortez, 2011. 104 p. 
FREIRE, P. Cartas a Cristina: reflexões sobre minha vida e minha práxis. 2. ed. São Paulo: UNESP, 2003b. 416 p.

FREIRE, P. Pedagogia da autonomia: saberes necessários à prática educativa. 25. ed. São Paulo: Paz e Terra, 2002. 150 p.

FREIRE, P. Pedagogia do oprimido. 35. ed. São Paulo: Paz e Terra, 2003a. 256 p.

FREITAS, A. L. S. et al. Leituras de Paulo Freire na partilha de experiências. Porto Alegre: EDIPUCRS, 2011. 112 p.

FONSECA, N. J S. Freire: reflexões e singularidades sobre a formação humana. In: GHIGGI, G. et al. Leituras de Paulo Freire: política, cultura e formação humana. São Leopoldo: Oikos, 2016. p. 30-43.

LÜCK, H. Gestão educacional: uma questão paradigmática. 11. ed. Petrópolis, RJ: Vozes, 2014. $120 \mathrm{p}$.

PALUDO, C. Educação popular em busca de alternativas: uma leitura desde o campo democrático popular. Porto Alegre: Tomo Editorial: 2001. 268 p.

PALUDO, C. Educação Popular. In: STRECK, D. R.; REDIN, E.; ZITKOSKI, J. (org.). Dicionário Paulo Freire. Lima: CEAAL, 2015. p. 176-178.

STRECK, D. Esperança. In: STRECK, D. R.; REDIN, E.; ZITKOSKI, J. (org.). Dicionário Paulo Freire. Lima: CEAAL, 2015. p. 202-203.

STRECK, D.; REDIN, E.; ZITKOSKI, J. J. (org.) Dicionário Paulo Freire. Lima: CEAAL. 2015. 448 p. ZITKOSKI, J. Dialética. In: STRECK, D. R.; REDIN, E.; ZITKOSKI, J. (org.). Dicionário Paulo Freire. Lima: CEAAL, 2015. p. 150-152.

Submetido em 29 de outubro de 2018.

Aprovado em 7 de janeiro de 2019. 